\title{
ITF

\section{Should players serve using the foot-up or foot-back technique?}

\section{Caroline Martin (FRA)}

ITF Coaching and Sport Science Review 2015; 67 (23): 22 - 24

\section{ABSTRACT}

In this article, two stance techniques used when serving, the foot-up and foot-back technique, will be analysed and the effects, practical tips and recommendations for each will be detailed for a variety of game styles and tactical intentions.
Key words: stance technique, foot-up, foot-back,

Received: 13 August 2015

Accepted: 14 September 2015 Corresponding author:

Caroline Martin

Email:

caromartin@numericable.fr

\section{INTRODUCTION}

In biomechanics, the tennis serve is a sequence of motions referred to as a "kinetic chain" made up of the various body segments involved in this specific stroke. As the starting point of this chain, the legs are the "launching pad" of the service motion and, therefore, their position and action play an essential role in performance. The goal of the preparation phase for the server, during which they get their body and legs into position, is to use ground reaction forces in order to generate the power required for the service motion. Tennis players can generally use two stance techniques: some bring the back foot up to the front foot during the ball toss, prior to the swing (Murray, Tsonga, Del Potro); while others leave the rear foot back until leg extension begins (Federer, Djokovic) (Figure 1). The first is known as the "foot-up" technique, while the second is called the "foot-back" technique.

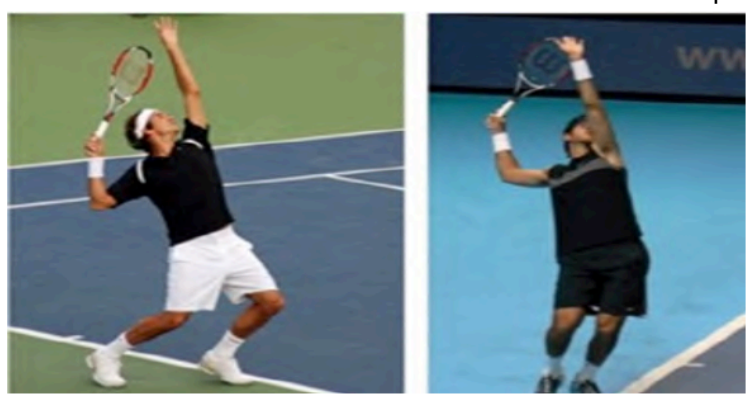

Figure 1. Foot-back tehcnique used by Federer (left); foot-up technique used by Del Potro (right).

During the 2007 French Open, the distribution of the two stance techniques was analysed (Renoult, 2007). Results showed that $72.4 \%$ of players used the foot-up technique. However, when we look at technique selection according to game style, we notice that this percentage changes considerably (Table 1). Close to $50 \%$ of players who serve and volley regularly or occasionally (doubles players or attacking players) use the foot-back stance when serving, compared with only 1 player in 6 among those who never move to the net after their serve (Table 1). What are the advantages and disadvantages of each stance technique?

\begin{tabular}{|c|c|c|}
\hline Serve stance & \multicolumn{1}{c|}{ Attacking game style } & Baseline game style \\
\hline Foot-up & $54.3 \%$ & $82.7 \%$ \\
\hline Foot-back & $45.7 \%$ & $17.3 \%$ \\
\hline
\end{tabular}

Table 1. Distribution of techniques according to game style among players at the French Open, adapted from Renoult (2007).

EFFECT OF THE STANCE TECHNIQUE ON BALL VELOCITY: ADVANTAGE TO THE FOOT-UP TECHNIQUE

A recent study has shown that when expert players use the foot-up technique, they generate on average higher ball velocities $(173.2 \mathrm{~km} / \mathrm{h}$ vs. $166.3 \mathrm{~km} / \mathrm{h}$ with the foot-back technique) (C. Martin, Bideau, Nicolas, Delamarche, \& Kulpa, 2012). This represents a mean difference of $7 \mathrm{~km} / \mathrm{h}$ in favour of the foot-up technique. How can we explain this result? It is known that the larger the base of support, the more balanced the player is. That is what happens with the foot-back technique which gives the player good stability. By contrast, with the foot-up technique, as both feet get closer until they touch one another and the server moves forward and pushes off the ground to hit the ball, the base of support narrows, which means the player becomes less balanced. The body of the server starts rotating forward. As the result of the blocking of a body part in motion (in this instance, the feet), an amount of body rotation is produced (as is also the case during a trip or somersault)

(Figure

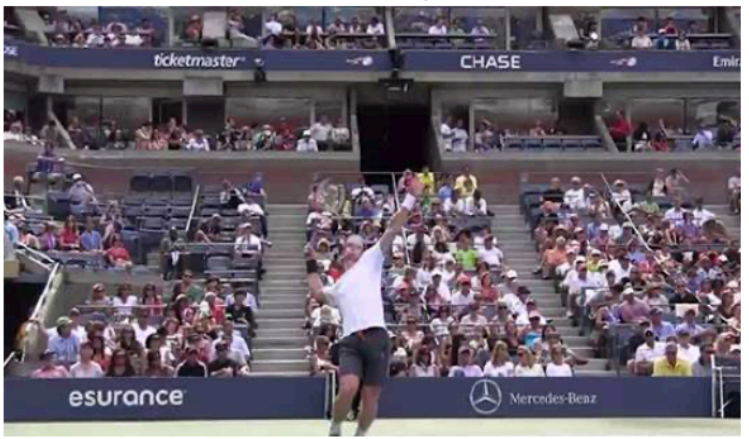

Figure 2. Back foot brought next to front foot before forward rotation.

That amount of forward body rotation (known as "angular momentum" in biomechanics) is greater with the foot-up technique than with the foot-back technique. And we know that the greater the amount of forward body rotation, the 
higher the ball velocity (Martin et al., 2013). That is why the foot-up stance allows players to serve a little harder.

\section{EFFECT OF THE STANCE TECHNIQUE ON NET CLEARANCE:} ADVANTAGE TO THE FOOT-UP TECHNIQUE

Another major advantage of the foot-up technique is that it produces higher upward ground reaction forces compared with the foot-back technique ( 2.1 times the body weight vs. 1.5 times the body weight, respectively) (Elliott \& Wood, 1983) (Bahamonde \& Knudson, 2001). onsequently, the foot-up technique allows players to impact the ball higher compared with the foot-back technique. A mean difference of $11 \mathrm{~cm}$ was recorded between the two stance techniques $(2.65 \mathrm{~m}$ with the foot-up technique vs. $2.54 \mathrm{~m}$ with the foot-back technique) in expert tennis players (Elliott \& Wood, 1983). As we know, the higher the ball impact, the greater the net clearance, the higher the chances of increasing 1st and 2nd serve percentages, and the more chances you have of achieving short and cross-court angles. It has been shown that increasing the height of ball impact from $2.60 \mathrm{~m}$ to $2.70 \mathrm{~m}$ allowed players to reach zones 25 to $30 \mathrm{~cm}$ shorter in the service box.

\section{EFFECT OF THE STANCE TECHNIQUE ON RUNNING TIME} TO THE NET DURING THE SERVE-AND-VOLLEY: ADVANTAGE TO THE FOOT-BACK TECHNIQUE

A scientific study has focused on the influence of stance techniques on the running time of expert tennis players (male and female) to the net during the serve-and-volley (Martin et al., 2012). Results showed that players using the foot-back technique were able to reach the service line faster than those using the foot-up technique $(1,49 \mathrm{~s}$ vs. $1.56 \mathrm{~s}$, respectively). Even though the difference of $70 \mathrm{~ms}$ between the two techniques may appear insignificant at first sight, in reality it makes quite a difference in relation to one of the biggest challenges of serve-and-volley play. Indeed, serve-and-volley players look to run as quickly as possible in order to play the volley in good conditions; this can be achieved by getting as close as possible to the net. For instance, in the case of a return of serve hit at $140 \mathrm{~km} / \mathrm{h}$, a $70 \mathrm{~ms}$ time difference means that the serve-and-volleyer can get approximately $2.4 \mathrm{~m}$ closer to the net, thus greatly enhancing the likelihood of a successful first volley (Figure 4). How is it possible to explain such a difference between the two stance techniques? According to the results of this study, the loss of time recorded with the foot-up technique happens mostly during the landing phase. The duration of the first foot-floor contact after the serve (Figure 3 ) is extended by 20 ms on average with the foot-up technique.

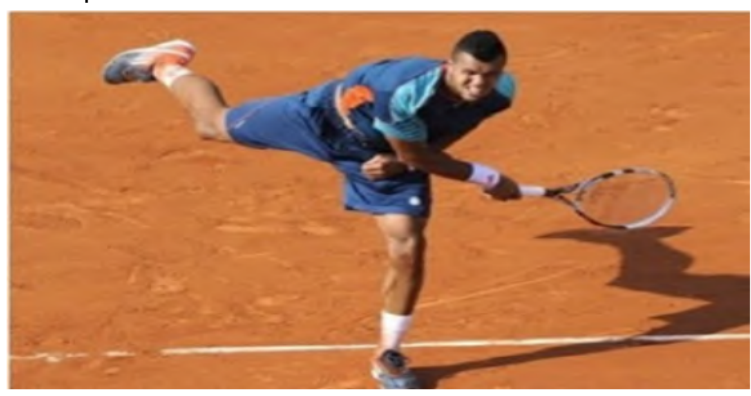

Figure 3. First foot-ground contact during the landing phase.

Because players push more upward when using the foot-up technique, they need more time to recover balance during the landing phase before running to the net. Another factor explains the shorter running time to the net with the foot-back technique, and that is the forward impulse. With the foot-back technique, players cover a greater distance inside the court during the serve $(60 \mathrm{~cm}$ compared with $46 \mathrm{~cm}$ with the foot-up technique) because they are able to generate larger propulsive forces to the net $(0.20$ times the body weight vs. 0.16 times the body weight with the foot-up technique) (Figure 4) (Elliott \& Wood, 1983) (Bahamonde \& Knudson, 2001).

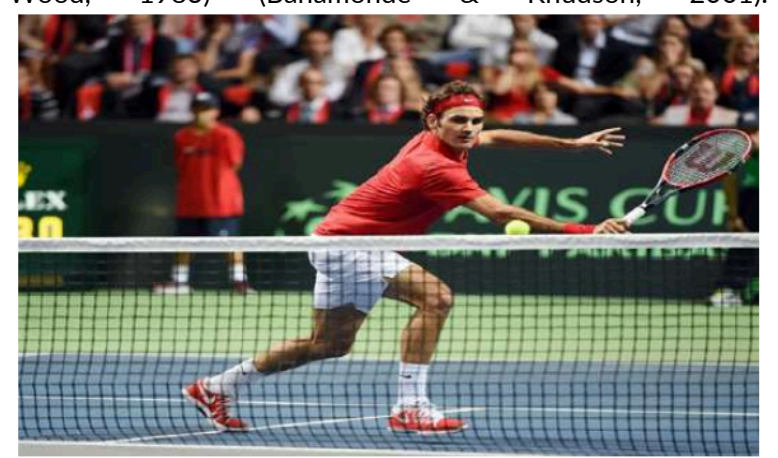

EFFECT OF THE STANCE TECHNIQUE ON THE RISKS OF CHRONIC UPPER LIMB JOINT INJURIES: NO CLEAR ADVANTAGE

Some scientists studied the stress (forces and torques) that is placed on the shoulder joint during the serving motion depending on the stance technique used in order to determine if one technique was more traumatic than the other. No noticeable difference in joint loading was observed between the foot-back and the foot-up techniques (Reid, Elliott, \& Alderson, 2008).

\section{CONCLUSION}

Practical tips: What type of stance is recommended when serving?

- Are you a doubles specialist? A serve-and-volleyer? Or an attacking player? Consider using the foot-back technique which will enable you to reach the net faster during the serveand-volley.

- Is your goal to serve with more speed and consistency? Consider using the foot-up technique to generate more speed and have a higher ball impact. Make sure to bring your back foot behind your front foot and not on the side or slightly in front. Otherwise, your hips will rotate towards the net too soon and you might overload and injure your shoulder.

- Is your goal to enhance the technique you currently use (footback or foot-up)? Regardless of the technique you use, you should know that it is the back leg that should primarily be responsible for pushing upward and forward; the role of the front leg is more to provide stability so as to facilitate the body rotation to the net. Make sure that your back foot is correctly positioned in relation to the back hip, i.e. in such a way that the upward push of the back leg allows for the elevation of the back hip and the tilting of the pelvis and shoulders (Figure 5).

\section{REFERENCES}

Bahamonde. R., and Knudson, D. (2001). Ground reaction forces and two types of stances and tennis serves. Medicine and Science in Sports and Exercise, 33(S1), 102.https://doi.org/10.1097/00005768200105001-00575

Elliott, B., Reid, M., \& Crespo, M. (2009). Technique development in tennis stroke production (pp. 71-88). International Tennis Federation.

Elliott, B., \& Wood, G. (1983). The biomechanics of foot-up and foot- back tennis service techniques. Australian Journal of Sports Sciences, 3(2), 3-6.

Martin, C., Bideau, B., Nicolas, G., Delamarche, P., \& Kulpa, R. (2012). How does the tennis serve technique 
influence the serve-and- volley ? Journal of Sports Sciences, 30(11),

$1149-$

1156.https://doi.org/10.1080/02640414.2012.695 079

Martin,C.,Kulpa,R.,Delamarche,P.,\&Bideau,B.(2013).Profession al tennis players' serve: correlation between segmental angular momentums and ball velocity. Sports Biomechanics, 12(1), 214.http://doi.org/10.1080/14763141.2012.73432

1.https://doi.org/10.1080/14763141.2012.734321

Reid, M., Elliott, B., \& Alderson, J. (2008). Lower-limb coordination and shoulder joint mechanics in the tennis serve. Medicine and Science in Sports and Exercise, 40(2), 308315.https://doi.org/10.1249/mss.0b013e31815c6 d61

Renoult, M. (2007). Les positions de départ au service et le relais d'appuis. La Lettre Du Club Fédéral Des Enseignants Professionnels de Tennis, (43), 2-3.
RECOMMENDED ITF TENNIS ACADEMY CONTENT (CLICK BELOW)

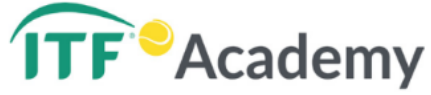

Copyright (c) Caroline Martin 2015

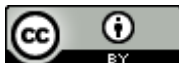

This text is under a Creative Commons BY 4.0 license

You are free to Share - copy and redistribute the material in any medium or format - and Adapt the content - remix, transform, and build upon the material for any purpose, even commercially under the following terms:

Attribution: You must give appropriate credit, provide a link to the license, and indicate if changes were made. You may do so in any reasonable manner, but not in any way that suggests the licensor endorses you or your use.

CCBY 4.0 license terms summary $\quad$ CCBY 4.0 license terms 